\title{
グロー放電発光分光分析における最適分析線の選択要件
}

\author{
我 妻 和 明*
}

\section{Criterion for determining the analytical emission lines in glow discharge optical emission spectrometry}

\author{
Kazuaki WaGATSUMA* \\ *Institute for Materials Research, Tohoku University, 2 - 1 - 1, Katahira, Aoba-ku, Sendai 980-8577
}

(Received 23 October 1998, Accepted 5 January 1999)

\begin{abstract}
Two major factors for selecting analytical lines, the sensitivity and the self-absorption effect, were compared between atomic lines and singly-ionized lines of copper as well as vanadium in glow discharge optical emission spectrometry. They have intense ionic lines which are excited through resonance charge-transfer collisions. It was found that the ionic lines are more sensitive compared to the atomic resonance lines; in addition, the ionic lines are essentially free from self-absorption, while the atomic lines suffer from self-absorption to a certain extent. The Cu II $224.70 \mathrm{~nm}$, V II $309.31 \mathrm{~nm}$, and V II $266.32 \mathrm{~nm}$ lines in the argon plasma, and the Cu II $270.32 \mathrm{~nm}$ line in the neon plasma are recommended as analytical lines of these elements.
\end{abstract}

Keywords : optical emission spectrometry; glow discharge plasma; analytical line; emission intensity; self-absorption; vanadium; copper.

\section{1 緒言}

発光分光分析において，スペクトル線の相対強度は使 用する励起源の特性に依存して大きく変化するため, そ れぞれの励起源に対して最適分析線を選択する必要があ ることが知られている．例えば, アーク放電プラズマの 場合には中性原子線が, また誘導結合プラズマの場合に は一価イオンの共鳴線が, 多くの元素において分析線と して適することが報告されている ${ }^{12)}$. グロー放電プラ ズマの場合には, 従来より既出のプラズマ励起源の研究 結果を参照とした分析線選定が行われてきたが, その励 起・電離過程は他のプラズマと異なることが明らかにな っており ${ }^{3 / 4)}$, グロー放電プラズマ励起源における最適

\footnotetext{
* 東北大学金属材料研究所: 980-8577 宮城県仙台市青 葉区片平 2-1-1
}

分析線の検討が必要とされる。特に，このプラズマでは 共鳴電荷移動衝突 ${ }^{5)}$ に起因する強度の高い一価イオン線 が多くの元素で観察されているが，これらの発光線を 発光分析に適用した研究はほとんど報告されていない.

鉄基標準試料を使用して評価した検出感度及び自己吸 収効果の 2 点より, グロー放電プラズマにおける最適 分析線を検討した。本報では, 従来のプラズマ励起源と は異なった推奨分析線が存在する事例として, 銅及びバ ナジウムについて報告する。

\section{2 実験}

グロー放電管は Grimm 型7)の基本構造を持つもので, 絶縁部分以外は真ちゅう製である ${ }^{8)}$. 中空陽極は内径 8 $\mathrm{mm}$ であり，陽極と陰極（試料）間距離は $0.2 \sim 0.3$ $\mathrm{mm}$ となるように調整した. プラズマガスはアルゴン 
Table 1 Observed emission lines of copper and vanadium, together with their assignments

\begin{tabular}{|c|c|c|}
\hline \multirow{2}{*}{$\begin{array}{l}\text { Wavelength/ } \\
\mathrm{nm}\end{array}$} & \multicolumn{2}{|c|}{ Assignment/eV ${ }^{9)}$} \\
\hline & Upper level & Lower level \\
\hline $\mathrm{Cu}$ I 324.75 & $4 p^{2} P_{3 / 2}(3.8166)$ & $4 \mathrm{~s}^{2} \mathrm{~S}_{1 / 2}(0.0000)$ \\
\hline $\mathrm{Cu}$ I 327.40 & $4 \mathrm{p}^{2} \mathrm{P}_{1 / 2}(3.7858)$ & $4 \mathrm{~s}^{2} \mathrm{~S}_{1 / 2}(0.0000)$ \\
\hline Cu I 510.55 & $4 p^{2} \mathrm{P}_{3 / 2}(3.8166)$ & $4 \mathrm{~s}^{2} \mathrm{D}_{5 / 2}(1.3889)$ \\
\hline $\mathrm{Cu}$ II 224.70 & $4 \mathrm{p}^{3} \mathrm{P}_{2}$ & $4 \mathrm{~s}^{3} \mathrm{D}_{3} \quad$ (2.7187) \\
\hline $\mathrm{Cu}$ II 270.32 & $5 \mathrm{~s}^{3} \mathrm{D}_{1} \quad(13.649)$ & $4 \mathrm{p}^{3} \mathrm{D}_{1}$ \\
\hline V I 318.40 & $4 p^{4} G_{5 / 2}(3.8927)$ & $4 \mathrm{~s}^{4} \mathrm{~F}_{3 / 2}(0.0000)$ \\
\hline V I 318.55 & $4 \mathrm{p}^{4} \mathrm{G}_{11 / 2}(3.9596)$ & $4 \mathrm{~s}^{4} \mathrm{~F}_{9 / 2}(0.0686)$ \\
\hline V II 266.32 & $4 \mathrm{~d}^{5} \mathrm{H}_{7} \quad(9.0532)$ & $4 p^{5} G_{6} \quad(4.3993)$ \\
\hline V II 309.31 & $4 p^{5} G_{6}$ & $4 \mathrm{~s}^{5} \mathrm{~F}_{5} \quad(0.3921)$ \\
\hline
\end{tabular}

（純度 99.9995\%）あるいはネオン（純度 99.99\%）を使 用し，放電管の主排気口に取り付けたピラニ真空計によ り導入ガス圧を制御した.

スペクトル線測定には日立 P-5200 型分光器を使用し た.この分光器は焦点距離 $750 \mathrm{~mm}$, ツェルニターナマ ウントの波長走查型であり, 本研究で使用した分光系は 波長範囲 190 440 nm, 回折格子 3600 grooves $/ \mathrm{mm}$, ブレーズ波長 $200 \mathrm{~nm}$ である．また，スリット幅 $10 \mu \mathrm{m}$ における実効分解能（スペクトル線半值全幅）は 0.007 nmである.

試料として, 日本鉄鋼連盟，蛍光 $\mathrm{X}$ 線分析用標準試 料の中から $\mathrm{Fe}-\mathrm{Cu}(\mathrm{FXS}-350 ， 351 ， 352 ）$ 及び $\mathrm{Fe}-\mathrm{V}$ （FXS-383，384，385）を使用した。これらの試料は, それぞれ銅を $0.20,0.50,1.00 \mathrm{~m} / \mathrm{m} \%$, 及びバナジウ ムを $0.49,1.00,2.04 \mathrm{~m} / \mathrm{m} \%$ 含む鉄基合金である.

\section{3 結果と考察}

Table 1 は検討した銅のスペクトル線の波長と帰属 ${ }^{9)}$ をまとめたものである。このうち一価イオン線 Cu II 224.70, Cu II $270.32 \mathrm{~nm}$ は, 電荷移動衝突による電 離・励起機構により，それぞれアルゴン，ネオングロー 放電プラズマより高い発光強度で観察されるスペクトル 線である ${ }^{10)}$. 一方, Cu I 324.75 及び Cu I $327.40 \mathrm{~nm}$ は 中性原子の共鳴線であり，グロー放電プラズマを含 む, 多くの発光分析用励起源で最適分析線と考えられて きたスペクトル線である.

Fig. 1 はアルゴングロー放電プラズマにより得られた Cu II 224.70(ム), Cu I 324.75 (○), Cu I $327.40 \mathrm{~nm}$ （ロ）の検量線を示したものである．Cu II $224.70 \mathrm{~nm}$ の 発光強度は中性原子の二重項共鳴線よりも大きく, 検出

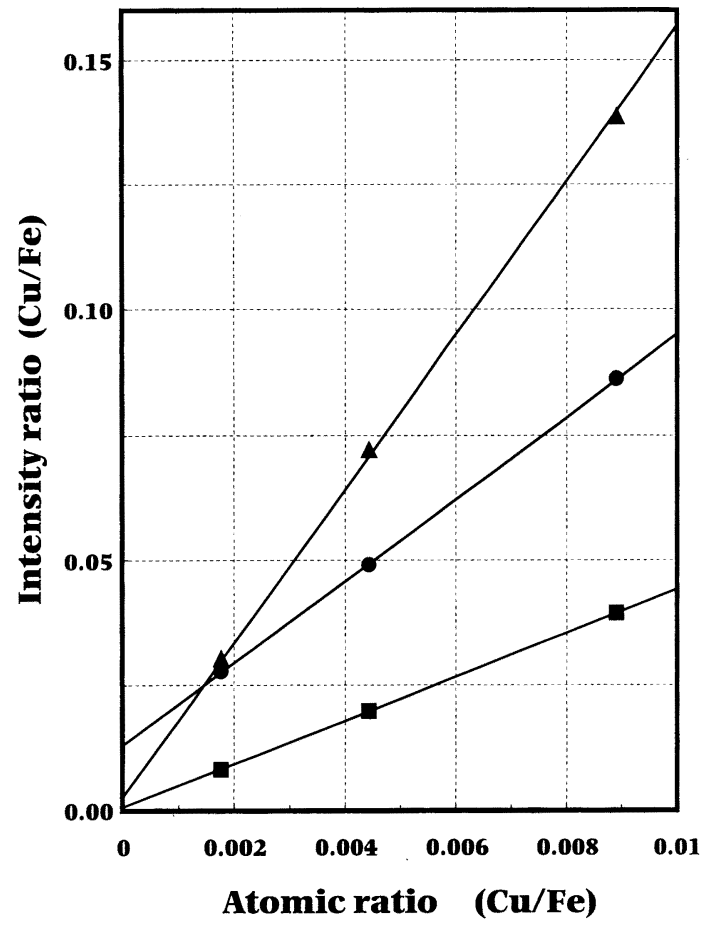

Fig. 1 Calibration curve of the intensity ratios: $\mathrm{Cu}$ I $324.75 / \mathrm{Fe}$ I 344.16 (O), Cu I $327.40 / \mathrm{Fe}$ I 344.16 $(\square)$, and Cu II 224.70/Fe I 344.16 ( $\Delta$ )

Discharge voltage/current: $500 \mathrm{~V} / 40 \mathrm{~mA}$; Ar pressure: $530 \mathrm{~Pa}$ (4 Torr)

感度についてはより優れた分析線であると考えられる。 更に, 鉄マトリックス固有の問題として, Fe II 324.75 $\mathrm{nm}$ の分光干渉により, Fig. 1 に示すように Cu I 324.75 $\mathrm{nm}$ の検量線は原点を通らない.このため, Cu I 324.75 $\mathrm{nm}$ を分析線とする微量濃度領域の分析は困難なものと なる. Fe II 324.75 nm はアルゴンプラズマにおいての み観察できるスペクトル線であり, その上位準位 $(4 \mathrm{p}$ $\left.{ }^{6} \mathrm{P}_{7 / 2}, 7.708 \mathrm{eV}\right)$ はアルゴンイオンと鉄原子の電荷移動 衝突において共鳴条件を満たすため, 飛躍的に準位密度 が増大することにより励起されていると考えられる ${ }^{11)}$. 発光強度は分光系や検出器感度の波長特性に左右される ため, Cu II $224.70 \mathrm{~nm}$ と二重項原子共鳴線の強度を厳 密に比較することは難しいが, Cu II $224.70 \mathrm{~nm}$ がそれ らと比べてそん色ない発光強度を示すことは注目に值す る.

分析線を選択する上で考慮するべき第二の要件とし て, 自己吸収現象の有無を挙げることができる. 自己吸 収が発光強度に影響を与える場合には, 検量線の直線範 


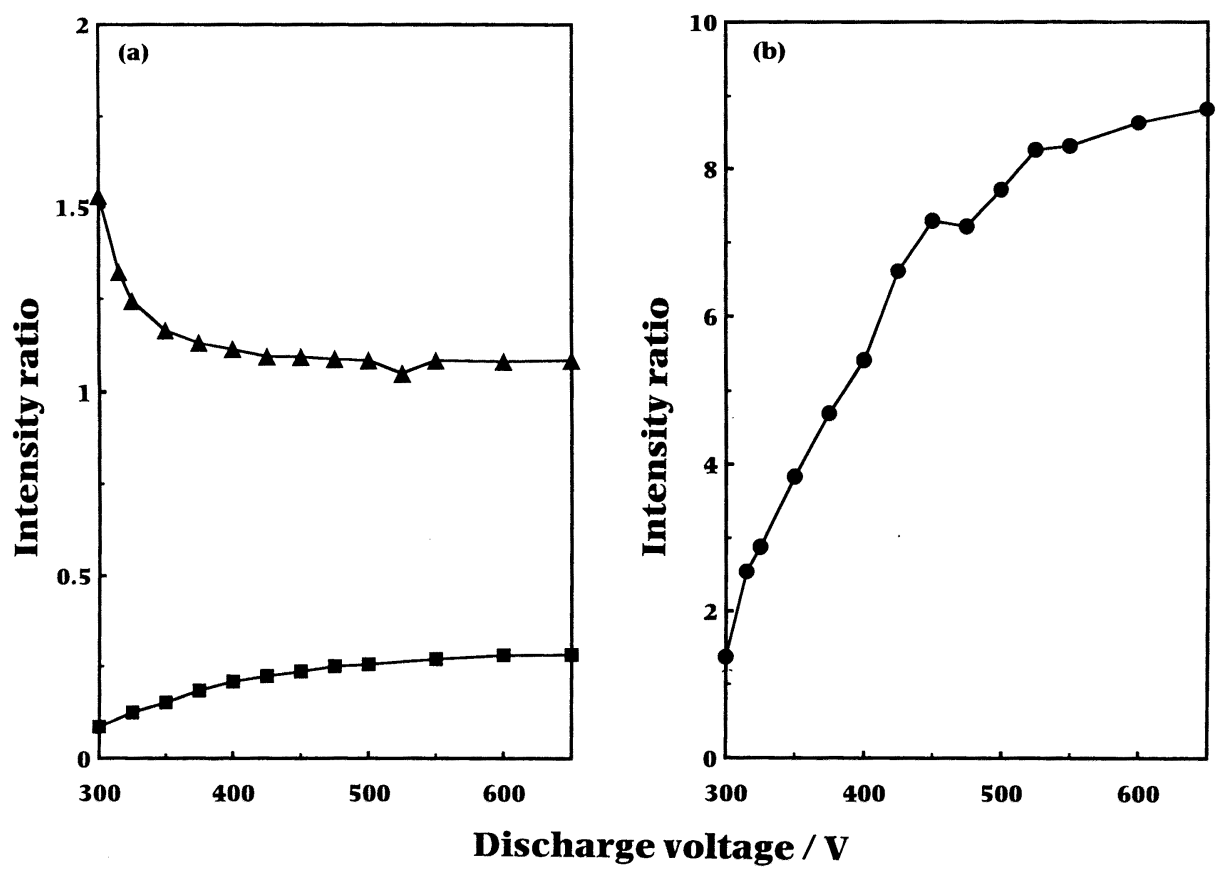

Fig. 2 Variation in the intensity ratios: Cu I 324.75/Cu I 327.40 (ㅅ), Cu I 510.55/Cu I 327.40 ( $\mathbf{\square})$, and Cu II $224.70 / \mathrm{Cu}$ I $327.40(\mathbf{)})$, as a function of the discharge voltage

Sample: copper plate (99.99\%) ; Ar pressure : $530 \mathrm{~Pa}$ (4 Torr)

囲が狭まり，また分析精度の低下の原因ともなり得る。 自己吸収効果が存在する場合でも, 試料と定量標準物質 のマトリックス組成をそろえるなど, 実験条件を厳密に 制御することにより発光強度から定量情報を得ることは 可能である. しかし，グロー放電発光分析のように固体 試料を直接分析する方法では, 適切な検量線用標準試料 が入手できない場合もあり，広範な実験条件で単一の検 量関係が成立することが望ましい，そのためには，自己 吸収の影響を受けにくい分析線を使用することが必要で ある。

Fig. 1 において, Fe II $324.75 \mathrm{~nm}$ の寄与を差し引い た Cu I 324.75 と Cu I $327.40 \mathrm{~nm}$ の間の発光強度比 $(\mathrm{Cu}$ I 324.75/Cu I 327.40）を見積もると，その值は大体 1.9 となる. 一方, 文献 ${ }^{12)} に$ 見いだされるこれらスペクトル 線の振動子強度の比は $2.1_{5}$ となる。振動子強度に 2 倍， 強の差異があるため, 自己吸収が顕著に起こっている環 境においては Cu I 324.75 nmがより多く吸収を受け, 結果としてその強度比は低下することが予想されるが, 実測強度比は振動子強度の比と大差がないことが分か る. したがって, 上記の実験結果は実測された発光強度
がほとんど自己吸収の影響を受けていないことを示して いるものと考えられる.これは, 試料中の銅の含有量が $1 \mathrm{~m} / \mathrm{m} \%$ 以下で，プラズマ中の銅原子密度が低いこと に起因している，ところが，試料を純銅にした場合には， かなり違った結果が得られる. Fig. 2 は Cu I $327.40 \mathrm{~nm}$

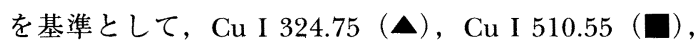
$\mathrm{Cu}$ II $224.70 \mathrm{~nm}$ (○) の強度比の放電電圧依存性を示 したものである.この場合試料として純銅を使用してい るため, Fig. 1の実験条件と比較してプラズマに導入さ れる銅原子の量は 2 けた程度多いと推定される. Table 1 に示したように, これら中性原子線はほぼ等しい励起 エネルギーを持つ上位準位が関与するスペクトル線であ るため, 類似した発光挙動を示すことが予想される.し かし実測結果では, 放電電圧の上昇により強度比（Cu I 324.75/Cu I 327.40）の減少が認められる.これはスパ ッタリング量（サンプリング量）の増大により, Cu I $327.40 \mathrm{~nm}$ と比較して Cu I $324.75 \mathrm{~nm}$ がより顕著に自 己吸収を受けたためであると考えられる. また, 強度比 （Cu I 510.55/Cu I 327.40）は逆に増加するが, これは Cu I 510.55 nm が非共鳴線で自己吸収を受けにくいこと 


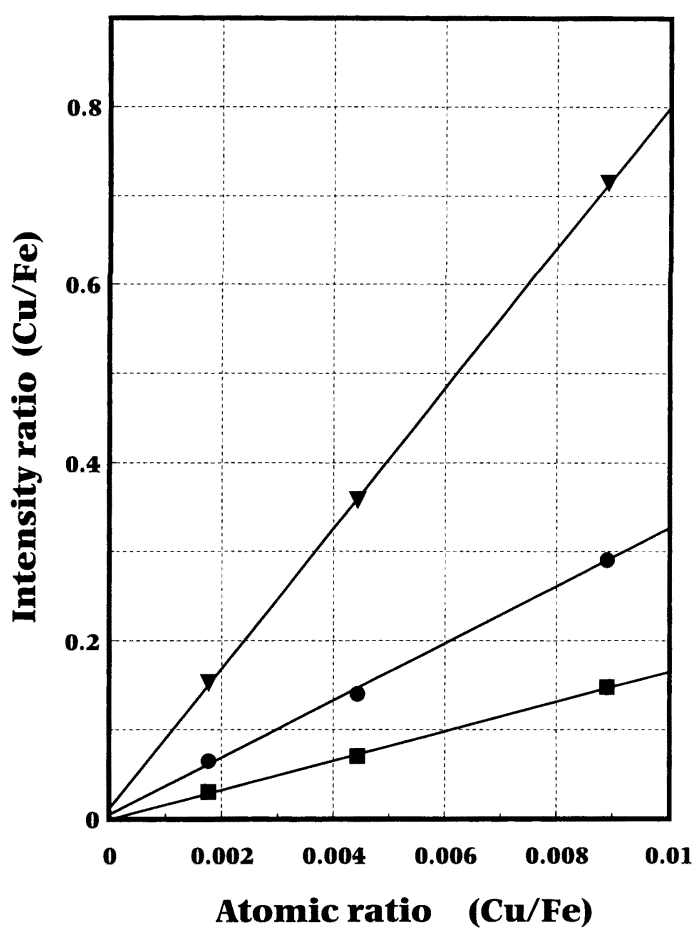

Fig. 3 Calibration curve of the intensity ratios: $\mathrm{Cu}$ I $324.75 / \mathrm{Fe}$ I $344.16(\bigcirc)$, Cu I $327.40 / \mathrm{Fe}$ I 344.16 (घ), and Cu II 224.70/Fe I 344.16

Discharge voltage/current: $800 \mathrm{~V} / 11.5 \mathrm{~mA}$; $\mathrm{Ne}$ pressure: $660 \mathrm{~Pa}$ (5 Torr)

を考虑すれば，分母である $\mathrm{Cu} \mathrm{I} 327.40 \mathrm{~nm}$ の発光強度 もまた Cu I $324.75 \mathrm{~nm}$ と同様に自己吸収の影響を受け ていることを示唆している. 更に, イオン線との強度比 （Cu II 224.70/Cu I 327.40）は，放電電圧の上昇に従っ

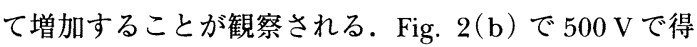
られた強度比は 7.8 であるのに対して, 放電電圧を同じ く $500 \mathrm{~V}$ に設定した Fig. 1のデータではその強度比は 3.5 となる。この差異は Cu I $327.40 \mathrm{~nm}$ が自己吸収を受 けその発光強度を減じたためであると考えられる，この ように, $\mathrm{Cu}$ I 324.75 と Cu I $327.40 \mathrm{~nm}$ の発光強度は自 己吸収の影響を受け，プラズマ中の $\mathrm{Cu}$ 原子密度に依存 して複雑な挙動をする。一方, Cu II $224.70 \mathrm{~nm}$ は一価 イオンの非共鳴線であるため自己吸収を受ける可能性は ほとんどないため，分析線としては最適である.

Fig. 3 はネオングロー放電プラズマにより得られた Cu II $270.32(\nabla)$, Cu I $324.75(\bullet)$, Cu I $327.40 \mathrm{~nm}$ （吕）の検量線を示したものである.Cu II $270.32 \mathrm{~nm}$ は ネオンプラズマにおいて特異的に励起される発光線であ

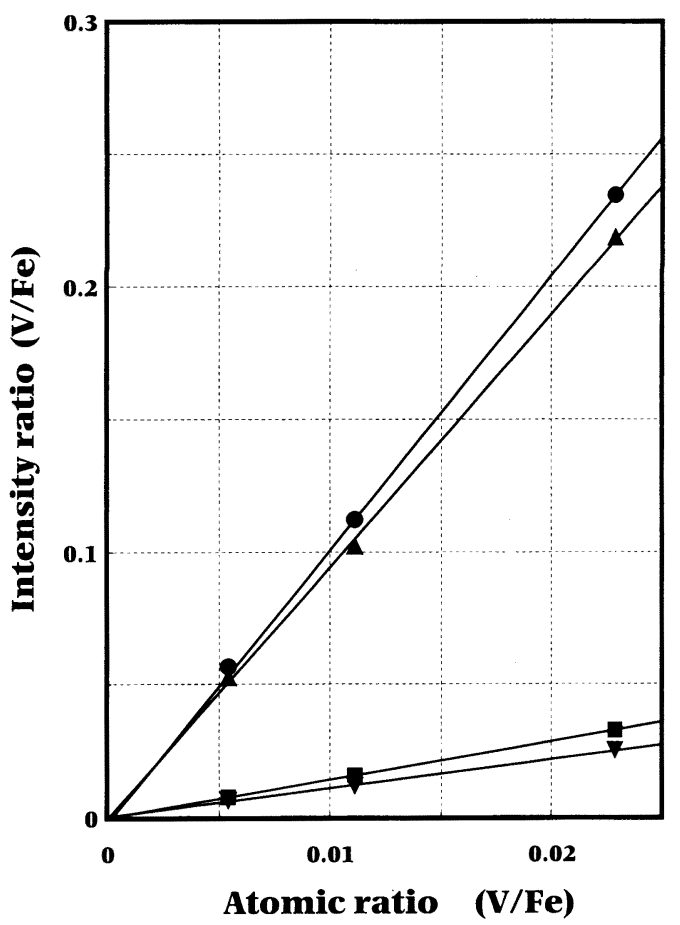

Fig. 4 Calibration curve of the intensity ratios: V I $318.55 /$ Fe I 344.16 ( $\boldsymbol{\nabla})$, V I $318.40 /$ Fe I 344.16 (ם), V II 266.32/Fe I 344.16 (A), and V II 309.31/ Fe I 344.16(

Discharge voltage/current: $500 \mathrm{~V} / 46 \mathrm{~mA}$; Ar pressure: $530 \mathrm{~Pa}$ (4 Torr)

り，アルゴンプラズマでは測定することができない(10). その強度は中性原子の二重項共鳴線よりもかなり大き く, 検出感度の観点から有利である。 また, 自己吸収現 象はアルゴンプラズマの場合と同様に，中性原子の共鳴 線で観察されるため，この点からも Cu II $270.32 \mathrm{~nm}$ を 分析線として選択することが適当である.

Fig. 4 はアルゴングロー放電プラズマにより得られた V II $309.31(\bullet)$, V II $266.32(\boldsymbol{\Delta})$, V I 318.40 及びV I $318.55 \mathrm{~nm}(\boldsymbol{\nabla})$ の検量線を示したものである. 一価イオン線の強度が 1 けた程度高く, 微量濃度領域 の分析線として最適である。また，銅の二重項原子共鳴 線と同様に,V I 318.40 及びV I $318.55 \mathrm{~nm}$ は原子吸光 分析にも使用されるスペクトル線で ${ }^{13)}$ ，バナジウムの存 在量によっては自己吸収を受けることが予想される、V II 266.32 は Cu II $224.70 \mathrm{~nm}$ と同じ励起機構により出現 すると推定されるスペクトル線であり，非共鳴線である ため自己吸収の心配がほとんどなく, 微量から高濃度領 
域まで幅広く適用可能な分析線と考えられる。

\section{文献}

1) 村山精一, 高橋 務: “固体試料分析のためのプ ラズマ発光法”, p. 123 (1982), (学会出版センタ 一).

2) 高橋 務, 村山精一: “溶液試料の発光分光分析 ーICPを中心として”, p. 150 (1983), (学会出版七 ンター).

3) E. B. M. Steers, R. J. Fielding: J. Atom. At. Spectrom., 2, 239 (1987).

4) K. Wagatsuma, K. Hirokawa: Anal. Chem., 57, 2901 (1985).

5) O. S. Duffendack, J. G. Black: Phys. Rev., 34, 35 (1929).

6) 我妻和明: 分析化学 (Bunseki Kagaku), 41, 353
(1992).

7) W. Grimm: Spectrochim. Acta, 23B, 443 (1968).

8) K. Wagatsuma, K. Hirokawa: Surf. Interface Anal., 6, 167 (1984)

9) C.E. Moore: "Atomic Energy Levels Vol. 2", NBS Stand. Circular 467, (1949), (US Government Printing Office).

10) K. Wagatsuma, K. Hirokawa: Spectrochim. Acta, 46B, 269 (1991).

11) K. Wagatsuma, K. Hirokawa: Spectrochim. Acta, 51B, 349 (1996).

12) C. H. Corliss, W. R. Bozman: "Experimental Transition Probabilities for Spectral Lines of Seventy Elements", NBS Monograph 53 (1962), (US Government Printing Office).

13）保田和雄，長谷川敬彦：“原子吸光分析”, p. 178 (1972), (講談社). 